\title{
APOPTOSIS BY DIETARY AGENTS FOR PREVENTION AND TREATMENT OF CANCER
}

\author{
Naghma Khan, Vaqar Mustafa Adhami, and Hasan Mukhtar ${ }^{*}$ \\ Department of Dermatology, University of Wisconsin, Madison, WI 53706, USA.
}

\begin{abstract}
The role of apoptosis or programmed cell death in the regulation of development and maintenance of homeostasis in multicellular organisms is well established. During the last decade, naturally occurring dietary agents known to produce chemopreventive effects in experimental models have been shown to target signaling intermediates in apoptosis-inducing pathways. Apoptosis is triggered by two different signals, one extrinsic, which responds mainly to extracellular stimuli, and the other intrinsic, activated by modulators within the cell itself. Proapoptotic compounds could protect against cancer by enhancing elimination of initiated, precancerous cells, and antiapoptotic compounds could promote tumor formation by inhibiting apoptosis in genetically damaged cells. In this brief review, we explore the potential mechanistic interactions of various dietary cancer chemopreventive components within the context of apoptosis.
\end{abstract}

\section{Keywords}

apoptosis; cancer; chemoprevention; dietary agents

\section{Introduction}

The term apoptosis is Greek for "falling of the leaves", and the term describes the distinctive phenotypic phenomenon related to cellular shrinkage. Apoptosis, however, is one specific mechanism of cell death which regulates tissue homeostasis through the elimination of potentially deleterious cells [1]. This regulated form of cell death is a complex process that involves the active participation of affected cells in a self-destruction cascade and is defined by a set of characteristic morphological hallmarks, including membrane blebbing, shrinkage of cell and nuclear volume, chromatin condensation and nuclear DNA fragmentation due to endonuclease activation. Apoptosis plays a critical role in physiological functions such as cell deletion during embryonic development, balancing of cell number in continuously renewing tissues and during immune system development [2]. Many diseases have been associated with aberrantly regulated apoptotic cell death, ultimately leading to inhibition of apoptosis and propagation of diseases such as cancer. Additionally, enhanced rates of apoptosis can contribute to degenerative diseases such as myocardial infarction, atherosclerosis, diabetes,

(C) 2008 Elsevier Inc. All rights reserved.

*Author for correspondence: Hasan Mukhtar, Ph.D., Helfaer Professor of Cancer Research, Director and Vice Chair for Research, Department of Dermatology, University of Wisconsin-Madison, 4385, Medical Sciences Center, 1300 University Avenue, Madison, WI 53706. Phone: 608-263-3927, Fax: 608-263-5223, E-mail: hmukhtar@wisc.edu.

Publisher's Disclaimer: This is a PDF file of an unedited manuscript that has been accepted for publication. As a service to our customers we are providing this early version of the manuscript. The manuscript will undergo copyediting, typesetting, and review of the resulting proof before it is published in its final citable form. Please note that during the production process errors may be discovered which could affect the content, and all legal disclaimers that apply to the journal pertain. 
reperfusion injury, Parkinson's disease and Alzheimer's disease whereas; inhibition of apoptosis can lead to proliferative diseases such as autoimmune disorders and cancer. The involvement of apoptosis in chemopreventive effects of dietary substances emerged ever since we provided the first evidence that (-)-epigallocatechin gallate (EGCG), the major constituent of green tea, at physiologically attainable concentrations causes induction of apoptosis and cell cycle arrest in many types of cancer cells without affecting normal cells. At present, a long list of such dietary constituents is known to induce apoptosis of cancer cells without affecting normal cells (Fig. 1) [3,4].

Apoptosis is controlled by two diverse pathways, the intrinsic or mitochondrial-mediated pathway and the extrinsic or death receptor-mediated pathway. The mitochondrial-mediated pathway involves the alteration of the mitochondrial membrane permeability, thereby promoting the release of cytochrome $c$ from mitochondria. Cytosolic cytochrome $c$ together with apoptosis protease activating factor (Apaf)-1 activates caspase-9, which in turn activates caspase- 3 resulting in apoptosis. Mitochondrial-mediated apoptosis is regulated by B-cell leukemia/lymphoma 2 (Bcl-2) family of proteins, which control mitochondrial membrane permeability [5]. In contrast, the death receptor-mediated pathway is initiated by the interaction of the ligand with its death receptor, which leads to the activation of caspase- 8 and caspase- 3 . The caspase-3 then cleaves various substrates leading to apoptosis [4]. The effects of dietary components on apoptosis are likely to be among the central mechanisms underlying associations between the consumption of diet and cancer. In the following sections, an overview of various signaling molecules that are targeted by various dietary components is provided with a particular focus on apoptosis.

\section{Dietary agents and the death receptor-mediated pathway Tumor necrosis factor (TNF)-related apoptosis inducing ligand (TRAIL)}

TRAIL acts as a homotrimer interacting with any one of five cognate receptors: TRAIL-R1, TRAIL-R2, TRAIL-R3, TRAIL-R4 and osteoprotegerin. TRAIL is expressed as a type II membrane protein and, similar to other membrane-bound ligands of the TNF superfamily, the extracellular domain of TRAIL can be processed by cysteine proteases and released in the serum [6]. We have recently reported that EGCG sensitizes TRAIL-resistant LNCaP cells to TRAIL-mediated apoptosis. Pretreatment of cells with EGCG resulted in modulation of deathinducing signaling cascade complex involving death receptor (DR)-4/TRAIL R1, Fasassociated protein with death domain (FADD) and FLICE-inhibitory protein [7]. Curcumin inhibited growth of LNCaP xenografts in nude mice by inducing apoptosis and inhibiting proliferation and sensitized these tumors to undergo apoptosis by TRAIL. In xenografted tumors, curcumin upregulated the expression of TRAIL-R1/DR4, TRAIL-R2/DR5, Bax, Bak, $\mathrm{p} 21 / \mathrm{WAF} 1$, and $\mathrm{p} 27 / \mathrm{KIP} 1$, and inhibited the activation of NF- $\mathrm{B}$ and its gene products [8]. Treatment with TRAIL in combination with genistein sensitized TRAIL-resistant AGS gastric adenocarcinoma cells to TRAIL-mediated apoptosis. Combined treatment with genistein and TRAIL caused activation of DR5 and induction of caspase-3 activity [9]. Pretreatment with a noncytotoxic concentration of luteolin, a dietary flavonoid commonly found in some medicinal plants significantly sensitized both TRAIL-sensitive as well as TRAIL-resistant cancer cells to TRAIL-induced apoptosis. [10].

Fas

Fas (CD95/APO-1) is a type I transmembrane protein belonging to the tumor necrosis factor superfamily of receptors. It was identified in 1989 as a cell death inducer of malignant human cancer and leukemia cell lines. Fas contain a classic "death domain" within its cytosolic tail, typical of a branch of the tumor necrosis factor family implicated in apoptosis induction [11]. It has been reported recently that treatment of MCF-7 cells with EGCG markedly inhibited 
heregulin (HRG)- $\beta$-1 dependent induction of FAS mRNA and protein. EGCG also decreased the phosphorylation of Akt and Erk1/2 that were demonstrated as selected downstream HRG11-responsive kinases required for FAS expression using dominant-negative Akt, PI3K inhibitors or MEK inhibitor. Additionally, growth inhibition of HRG- $\beta 1$-treated cells was parallel to suppression of FAS by EGCG [12]. In multiple myeloma cells, EGCG treatment activated distinct pathways of growth arrest and apoptosis by inducing the expression of deathassociated protein kinase 2, Fas ligand, Fas, and caspase-4, positive regulators of apoptosis and NF- $\mathrm{KB}$ activation and cyclin-dependent kinase inhibitors [13]. We have shown that lupeol, a triterpene present in fruits and vegetables, specifically caused a significant increase in the expression of Fas receptor with a significant increase in the expression of FADD protein. The small interfering RNA-mediated silencing of the Fas gene and inhibition of caspase-6, caspase- 8 , and caspase- 9 by their specific inhibitors confirmed that lupeol specifically activates the Fas receptor-mediated apoptotic pathway in androgen-sensitive prostate cancer cells [14]. Resveratrol induces the clustering of Fas and its redistribution in cholesterol and sphingolipidrich fractions of SW480 human colon cancer cells, together with FADD and procaspase-8. This redistribution is associated with the formation of a death-inducing signaling complex [15]. Curcumin has been reported to induce apoptosis in human melanoma cells through a Fas receptor/caspase-8 pathway independent of p53 [16].

\section{Cellular FADD like interleukin-1- $\beta$-converting enzyme inhibitory protein (c-FLIP)}

The c-FLIP is able to modulate activation of procaspase- 8 and thereby prevents induction of apoptosis mediated by death receptors. Treatment with silibinin in combination with TRAIL induced rapid apoptosis in TRAIL-resistant glioma cells and downregulated the protein levels of the antiapoptotic proteins FLIP $_{L}$, FLIP $_{S}$ and survivin through proteasome-mediated degradation [17]. Treatment of MDA-231 cells with sanguinarine caused reduction in protein levels of pro-caspase-3, Bcl-2, cIAP2, XIAP, and c-FLIPs [18]. An indole compound, 3, 3'diindolylmethane, derived from cruciferous vegetables led to significant down-regulation of the c-FLIP which was predominantly mediated by the ubiquitin-proteasome degradation system [19].

\section{Dietary agents and the mitochondrial-mediated pathway}

\section{Activation of Caspases}

Caspases are an evolutionary conserved family of cysteine proteases that are responsible for diverse cellular functions including inflammation and apoptosis [20]. Features common to all members in this family of proteases include the catalytic cysteine residue in the active site and the ability to cleave substrates on the carboxyl side of aspartate residues. The caspases- $2,-8$, $-9,-10,-12$ are known as initiator caspases and caspases-3, $-6,-7,-14$ are called as effector caspases. Initiator caspases function upstream within apoptotic signaling pathways. They are capable of activating downstream effector caspases either directly, through proteolysis, or indirectly via a secondary messenger mechanism. Upon activation by an initiator caspase, effector caspases are immediate "executioners of the apoptotic program", cleaving certain cellular substrates to cause demolition of the cell [21]. We have reported that treatment of human PCa cells LNCaP, PC-3, and CWR22Rv1 with combination of EGCG and Cox-2 inhibitor resulted in enhanced cell growth inhibition, activation of caspases, apoptosis induction and inhibition of NF-кB [22]. We have shown recently that treatment of PCa cells with fisetin resulted in significant activation of caspase-3, -8 and -9 . Pretreatment of cells with caspase inhibitor blocked fisetin-induced activation of caspases [23]. Apigenin and TRAIL at suboptimal concentrations induced Bid cleavage and the activation of caspases- $8,-10,-9$, and -3 in malignant tumor cells [24]. Resveratrol has been shown to induce apoptosis in human breast cancer cells primarily through the caspase-3-dependent pathway [25]. We have earlier reported that EGCG treatment of A431 cells resulted in significant activation of caspases, as 
shown by the dose- and time-dependent increase in DEVDase activity, and protein expression of caspase-3, -8 and -9. EGCG-mediated induction of apoptosis was blocked by the caspase inhibitor in these cells [26]. Genistein induced apoptosis in acute promyelocytic leukemia derived NB4 cells is mediated by activation of caspase- 9 and -3 and associated with a decrease in mitochondrial transmembrane potential and cytosolic release of cytochrome c [27]. Treatment of LNCaP cells with curcumin resulted in translocation of Bax and p53 to mitochondria, production of reactive oxygen species, activation of caspase- 3 and induction of apoptosis [28]. Pretreatment with luteolin sensitized TRAIL-induced apoptosis in both TRAILsensitive (HeLa) and TRAIL-resistant cancer cells (CNE1, HT29, and HepG2) through enhanced caspase-8 activation and caspase-3 maturation [10].

\section{Alteration of $\mathrm{Bax} / \mathrm{Bcl}-2$ ratios}

It is widely accepted that a cell's commitment to undergo apoptosis partly depends upon the balance between proteins that mediate cell death and also on the ratio of $\mathrm{Bax} / \mathrm{Bcl}-2$ which appears to be a critical determinant of a cell's threshold for undergoing apoptosis. Treatment with EGCG and GTP caused an increase in Bax, reduction in Bcl-2 and PARP cleavage in MDA-MB-231 human breast cancer cells [29]. Fisetin treatment resulted in induction of apoptosis, PARP cleavage, increase in Bax, decrease in Bcl-2 and modulation in the expressions of Bcl-2-family proteins in human PCa cells [23]. We have reported that treatment of delphinidin caused activation of caspases, increase in Bax, decrease in Bcl-2, upregulation of Bid and Bak and downregulation of Bcl-xL in HaCaT cells and inhibition of UVB-mediated apoptosis in SKH-1 hairless mice [30]. We have reported that pomegranate fruit extract (PFE) caused an increase in the protein expression of Bax and decrease in Bcl-2 in a dose-dependent fashion in PC-3 cells. There was also a significant dose-dependent shift in the ratio of Bax to Bcl-2 after PFE treatment, indicating the induction of an apoptotic process [31]. In DMBAinitiated and TPA promoted mouse skin tumors, resveratrol application induced the expression of $\mathrm{p} 53$ and Bax, with concomitant decrease in Bcl-2. Alteration in Bax/Bcl-2 ratio by resveratrol treatment resulted in apoptosis, which was associated with the release of cytochrome $c$ and induction of apoptotic protease activating factor 1 (Apaf-1) [32]. There was induction of mitochondrial transmembrane potential alteration, cytochrome $c$ release and downregulation of Bcl-2 and induction of Bax protein expression in human T lymphoma Jurkat cells by dietary ginger constituents [33].

\section{Mitochondrial polarization/depolarization}

Mitochondria are key regulators of cell life and death and play an important role in a wide range of diseases, including cancer, diabetes, cardiovascular disease, and the age-related neurodegenerative diseases. The unique structural and functional characteristics of mitochondria enable the selective targeting of drugs designed to modulate the function of this organelle for therapeutic gain. The mitochondrial permeability transition pore (MTP) is a multiprotein complex at contact sites of the inner with the outer mitochondrial membrane. Research over the past several years has led to the concept that the MTP occupies a central role in cell death induction. Numerous apoptosis signals convert this protein aggregate into an unspecific pore, thus activating mitochondria for the cellular self-destruction process. In human pancreatic cancer cells, EGCG induced Bax oligomerization, depolarization of mitochondrial membranes to facilitate cytochrome $c$ release into cytosol and caspase-dependent apoptosis [34]. In human tongue squamous carcinoma CAL-27 cells, both green and black tea polyphenols transduced the apoptosis signal via generation of reactive oxygen species and decrease in the $\mathrm{Bax} / \mathrm{Bcl}-2$ ratio thereby inducing mitochondrial permeability transition with consequent activation of caspase-3 [35]. Treatment of HepG2 cells challenged with curcumin for $1 \mathrm{~h}$ showed a transient elevation of the mitochondrial membrane potential followed by cytochrome $c$ release into the cytosol [36]. Delphinidin, an anthocyanidin in pigmented fruits and vegetables has been shown to cause nuclear condensation and fragmentation, PARP cleavage and loss of mitochondrial 
membrane potential of apoptotic cells in uterine carcinoma and colon adenocarcinoma cells [37]. Genistein has been shown to cause induction of apoptosis in T lymphoma cells via mitochondrial damage with the involvement of the MTP [38]. Capsaicin, the major pungent ingredient in red peppers, induced apoptosis in prostate cells by a mechanism involving reactive oxygen species generation, dissipation of the mitochondrial inner transmembrane potential and activation of caspase-3. Subcutaneous injection of capsaicin in nude mice suppressed PC-3 tumor growth in all tumors investigated and induced apoptosis of tumor cells [39]. Allyl and benzyl isothiocyanates caused disruption of mitochondrial membrane potential, activation of multiple caspases, arrest of cell cycle progression, and induction of differentiation in human leukemia cells [40]. In malignant human pancreatic cancer cells, resveratrol caused damage of mitochondrial function that lead to increased ROS, apoptosis and possibly intracellular drug accumulation via inhibition of proteins involved in multi-drug resistance [41].

\section{Mitochondrial cytochrome c release}

The mitochondria is a very central apparatus in cell death signaling through its ability to differentially regulate the trafficking of pro and anti-apoptotic proteins depending on the type of stimulus within its inter-membrane space [42]. The release of cytochrome $c$ is known to occur through two main mechanisms; MTP-dependent and MTP-independent mechanisms. In the MTP-dependent mechanism, the mitochondrial pores open, followed by the movement of cytochrome $c$ from the inter-membrane space which then complexes with Apaf-1, ATP and procaspase-9 to form the "apoptosome". Several agents have the ability to induce MTP and lead to the formation of the apoptosome and activation of caspase-9, which in turn activates downstream caspase- 3 , which causes caspase- 6 activation and then drives the caspase cascade and the cell death mechanism. The release of anti-apoptotic Bcl-2 protein family is known to regulate apoptosis through inhibition of cytochrome $c$ and Apaf-1 release by mechanisms that may involve channel formation activity and displacement of Apaf-1 from a complex of proteins. In pancreatic cancer cells, EGCG induced apoptosis and depolarization of mitochondrial membranes to facilitate cytochrome $c$ release into cytosol. EGCG-induced downregulation of IAP family member X chromosome linked inhibitor of apoptosis protein (XIAP) might be helpful to facilitate cytochrome $c$ mediated downstream caspase activation [34].

Lycopene reduced mitochondrial transmembrane potential, induced the release of mitochondrial cytochrome $c$ and increased annexin $\mathrm{V}$ binding confirming induction of apoptosis in LNCaP human PCa cells [43]. Ellagitannins of pomegranate fruit caused induction of apoptosis via intrinsic pathway through Bcl-XL down-regulation with mitochondrial release of cytochrome $c$ into the cytosol, activation of initiator caspase- 9 and effector caspase- 3 in human colon cancer cells [44]. Genistein has been reported to induce apoptosis mediated by activation of caspase- $9,-3$ and was associated with a decrease in mitochondrial transmembrane potential and cytosolic release of cytochrome $c$ in acute promyelocytic leukemia derived NB4 cells [27]. We have recently shown that fisetin caused induction of apoptosis, PARP cleavage, modulation in the expressions of Bcl-2-family proteins, and induction of mitochondrial release of cytochrome $c$ into cytosol in human PCa cells [23].

The p53 tumor suppressor protein is often referred to as the "guardian of the genome" as its response to DNA-damage or checkpoint failure gives rise to a series of anti-proliferative responses. One of the most important functions of p53 is its ability to induce apoptosis and disruption of this route can promote tumor progression and chemoresistance. Besides its ability to promote apoptosis through transcription dependent mechanisms, p53 may also be able to activate apoptosis independent of transcriptional regulation. Therefore, to ensure normal cell growth, p53 levels and activity are tightly regulated [45]. The p53 pathway is inactivated in 
majority of human cancers, most likely because the proapoptotic function of p53 is critical to the inhibition of tumor development and progression. In T47D human breast cancer cells, transresveratrol induced apoptosis which was associated with the activation of the p53 in a doseand time-dependent manner. PI3K inhibitors abolished the effect of trans-resveratrol on p53 activation [46]. We have demonstrated using isogenic cell lines that EGCG activates growth arrest and apoptosis in prostate carcinoma cells primarily via p53-dependent pathway that involves the function of both $\mathrm{p} 21$ and Bax such that down-regulation of either molecule confers a growth advantage to the cells [47]. Recently, silibinin has been shown to cause downregulation of survivin and an increase in p53 expression together with enhanced apoptosis in human bladder tumors [48]. Genistein induced G2/M phase cell cycle arrest, apoptosis, increase in p53 and p21 levels in human malignant glioma cell lines [49].

\section{Survivin}

Survivin is a member of the inhibitor of apoptosis protein (IAP) family that acts as a suppressor of apoptosis and plays a central role in cell division. Survivin is expressed during embryonal development but is absent in most normal, terminally differentiated tissues. It is overexpressed in several human neoplasms and currently survivin protein expression is being used as a prognostic factor in several human neoplasms. High survivin expression by neoplasms correlates with more aggressive behavior, decreased response to chemotherapeutic agents and shortened survival times as compared with cancers that are survivin negative [50]. Tamoxifen and genistein combination synergistically induced apoptosis in human breast cancer BT-474 cells in part by synergistic downregulation of the expression of survivin and downregulation of EGFR, HER2, and ER $\alpha$ expression [51]. The anti-apoptotic Bcl-2 and survivin protein was downregulated by curcumin treatment together with enhancement of the Bax and p53 expression in human bladder cancer cells [52]. The major acid-catalyzed reaction product of indole-3-carbinol (I3C), 3,3'-diindolylmethane (DIM) inhibited cell growth and induced apoptosis in MDA-MB-231 breast cancer cells by down-regulating survivin, Bcl-2, and cdc25A expression and also caused up-regulation of p21/WAF1 expression. Down-regulation of survivin by small interfering RNA before DIM treatment resulted in enhanced cell growth inhibition and apoptosis, whereas overexpression of survivin by cDNA transfection abrogated DIM-induced cell growth inhibition and apoptosis in MDA-MB-231 breast cancer cells [53]. In human breast cancer cells, EGCG treatment decreased both mRNA and protein expression of survivin and the survivin-promoter luciferase activity was also significantly inhibited [54].

\section{Conclusions and Perspectives}

Epidemiological studies showing a protective effect of diets rich in fruits and vegetables against cancer have stressed on the possibility that naturally occurring phytochemicals can exert anticarcinogenic activity. Evidence is also accumulating to support the notion that provision of a combination of dietary bioactive agents is more effective than treatment with a single dietary component. Thus, it is reasonable to assume that combinations of components could be designed to either target multiple pathways or exhibit potentiation or synergy of specific pathways. The interaction of components of the diet clearly requires more focus and further research. It appears that several molecular targets exist in vivo and collectively converge on various signaling pathways. Thus, using combinatorial therapy, dietary agents may affect many targets each leading to the induction of apoptosis. There is ample evidence to suggest that the cancer-protective effects of an individual's diet may reflect the synergistic effects of various vitamins, minerals and other bioactive components rather than from the effect of a single ingredient. To determine the merit of combining foods for maximum efficacy for cancer prevention, a better understanding of physiologically important interactions is needed. By determining the fundamental mechanisms of apoptosis regulation and identification of the various cell survival genes that become dysregulated in tumors, several therapeutic 
opportunities have been revealed. To fully establish the utility of the apoptotic markers in cancer management, large-scale evaluation of the apoptotic markers in conjunction with multiple clinical parameters and other biochemical markers are encouraged.

\section{Acknowledgments}

The original work from the author's (HM) laboratory outlined in this review was supported by United States Public Health Service Grants RO1 CA 78809, RO1 CA 101039, RO1 CA 120451 and P50 DK065303.

\section{References}

1. Holdenrieder S, Stieber P. Apoptotic markers in cancer. Clin Biochem 2004;37:605-617. [PubMed: 15234242]

2. Danial NN, Korsmeyer SJ. Cell death: critical control points. Cell 2004;116:205-219. [PubMed: 14744432]

3. Ahmad N, Feyes DK, Nieminen AL, Agarwal R, Mukhtar H. Green tea constituent epigallocatechin-3gallate and induction of apoptosis and cell cycle arrest in human carcinoma cells. J Natl Cancer Inst 1997;89:1881-1886. [PubMed: 9414176]

4. Khan N, Afaq F, Mukhtar H. Apoptosis by dietary factors: the suicide solution for delaying cancer growth. Carcinogenesis 2007;28:233-239. [PubMed: 17151090]

5. Green DR, Kroemer G. The pathophysiology of mitochondrial cell death. Science 2004;305:626-629. [PubMed: 15286356]

6. Secchiero P, Zauli G. Tumor-necrosis-factor-related apoptosis-inducing ligand and the regulation of hematopoiesis. Curr Opin Hematol 2008;15:42-48. [PubMed: 18043245]

7. Siddiqui IA, Malik A, Adhami VM, Asim M, Hafeez BB, Sarfaraz S, et al. Green tea polyphenol EGCG sensitizes human prostate carcinoma LNCaP cells to TRAIL-mediated apoptosis and synergistically inhibits biomarkers associated with angiogenesis and metastasis. Oncogene 2008;27:2055-2063. [PubMed: 17998943]

8. Shankar S, Ganapathy S, Chen Q, Srivastava RK. Curcumin sensitizes TRAIL-resistant xenografts: molecular mechanisms of apoptosis, metastasis and angiogenesis. Mol Cancer 2008;7:16. [PubMed: 18226269]

9. Jin CY, Park C, Cheong J, Choi BT, Lee TH, Lee JD, et al. Genistein sensitizes TRAIL-resistant human gastric adenocarcinoma AGS cells through activation of caspase-3. Cancer Lett 2007;257:56-64. [PubMed: 17689858]

10. Shi RX, Ong CN, Shen HM. Protein kinase C inhibition and $x$-linked inhibitor of apoptosis protein degradation contribute to the sensitization effect of luteolin on tumor necrosis factor-related apoptosis-inducing ligand-induced apoptosis in cancer cells. Cancer Res 2005;65:7815-7823. [PubMed: 16140950]

11. Hyer ML, Samuel T, Reed JC. The FLIP-side of Fas signaling. Clin Cancer Res 2006;12:5929-5931. [PubMed: 17028246]

12. Pan MH, Lin CC, Lin JK, Chen WJ. Tea polyphenol (-)-epigallocatechin 3-gallate suppresses heregulin-beta1-induced fatty acid synthase expression in human breast cancer cells by inhibiting phosphatidylinositol 3-kinase/Akt and mitogen-activated protein kinase cascade signaling. J Agric Food Chem 2007;55:5030-5037. [PubMed: 17539658]

13. Shammas MA, Neri P, Koley H, Batchu RB, Bertheau RC, Munshi V, et al. Specific killing of multiple myeloma cells by (-)-epigallocatechin-3-gallate extracted from green tea: biologic activity and therapeutic implications. Blood 2006;108:2804-2810. [PubMed: 16809610]

14. Saleem M, Kweon MH, Yun JM, Adhami VM, Khan N, Syed DN, et al. A novel dietary triterpene Lupeol induces fas-mediated apoptotic death of androgen-sensitive prostate cancer cells and inhibits tumor growth in a xenograft model. Cancer Res 2005;65:11203-11213. [PubMed: 16322271]

15. Delmas D, Rebe C, Lacour S, Filomenko R, Athias A, Gambert P, et al. Resveratrol-induced apoptosis is associated with Fas redistribution in the rafts and the formation of a death-inducing signaling complex in colon cancer cells. J Biol Chem 2003;278:41482-41490. [PubMed: 12902349] 
16. Bush JA, Cheung KJ Jr, Li G. Curcumin induces apoptosis in human melanoma cells through a Fas receptor/caspase-8 pathway independent of p53. Exp Cell Res 2001;271:305-314. [PubMed: 11716543]

17. Son YG, Kim EH, Kim JY, Kim SU, Kwon TK, Yoon AR, et al. Silibinin sensitizes human glioma cells to TRAIL-mediated apoptosis via DR5 up-regulation and down-regulation of c-FLIP and survivin. Cancer Res 2007;67:8274-8284. [PubMed: 17804742]

18. Kim S, Lee TJ, Leem J, Choi KS, Park JW, Kwon TK. Sanguinarine-induced apoptosis: generation of ROS, down-regulation of Bcl-2, c-FLIP, and synergy with TRAIL. J Cell Biochem 2008;104:895907. [PubMed: 18189268]

19. Zhang S, Shen HM, Ong CN. Down-regulation of c-FLIP contributes to the sensitization effect of 3,3'-diindolylmethane on TRAIL-induced apoptosis in cancer cells. Mol Cancer Ther 2005;4:19721981. [PubMed: 16373712]

20. Degterev A, Boyce M, Yuan J. A decade of caspases. Oncogene 2003;22:8543-8567. [PubMed: 14634618]

21. Ho PK, Hawkins CJ. Mammalian initiator apoptotic caspases. FEBS J 2005;272:5436-5453. [PubMed: 16262685]

22. Adhami VM, Malik A, Zaman N, Sarfaraz S, Siddiqui IA, Syed DN, et al. Combined inhibitory effects of green tea polyphenols and selective cyclooxygenase-2 inhibitors on the growth of human prostate cancer cells both in vitro and in vivo. Clin Cancer Res 2007;13:1611-1619. [PubMed: 17332308]

23. Khan N, Afaq F, Syed DN, Mukhtar H. Fisetin, a novel dietary flavonoid causes apoptosis and cellcycle arrest in human prostate cancer LNCaP cells. Carcinogenesis. 2008 (PMID: 18359761).

24. Horinaka M, Yoshida T, Shiraishi T, Nakata S, Wakada M, Sakai T. The dietary flavonoid apigenin sensitizes malignant tumor cells to tumor necrosis factor-related apoptosis-inducing ligand. Mol Cancer Ther 2006;5:945-951. [PubMed: 16648565]

25. Alkhalaf M, El-Mowafy A, Renno W, Rachid O, Ali A, Al-Attyiah R. Resveratrol-induced apoptosis in human breast cancer cells is mediated primarily through the caspase-3-dependent pathway. Arch Med Res 2008;39:162-168. [PubMed: 18164959]

26. Gupta S, Hastak K, Afaq F, Ahmad N, Mukhtar H. Essential role of caspases in epigallocatechin-3gallate-mediated inhibition of nuclear factor kappa B and induction of apoptosis. Oncogene 2004;23:2507-2522. [PubMed: 14676829]

27. Ng AP, Nin DS, Fong JH, Venkataraman D, Chen CS, Khan M. Therapeutic targeting of nuclear receptor corepressor misfolding in acute promyelocytic leukemia cells with genistein. Mol Cancer Ther 2007;6:2240-2248. [PubMed: 17699721]

28. Shankar S, Srivastava RK. Involvement of Bcl-2 family members, phosphatidylinositol 3'-kinase/ AKT and mitochondrial p53 in curcumin (diferulolylmethane)-induced apoptosis in prostate cancer. Int J Oncol 2007;30:905-918. [PubMed: 17332930]

29. Thangapazham RL, Passi N, Maheshwari RK. Green tea polyphenol and epigallocatechin gallate induce apoptosis and inhibit invasion in human breast cancer cells. Cancer Biol Ther 2007;6:19381943. [PubMed: 18059161]

30. Afaq F, Syed DN, Malik A, Hadi N, Sarfaraz S, Kweon MH, et al. Delphinidin, an anthocyanidin in pigmented fruits and vegetables, protects human HaCaT keratinocytes and mouse skin against UVBmediated oxidative stress and apoptosis. J Invest Dermatol 2007;127:222-232. [PubMed: 16902416]

31. Malik A, Afaq F, Sarfaraz S, Adhami VM, Syed DN, Mukhtar H. Pomegranate fruit juice for chemoprevention and chemotherapy of prostate cancer. Proc Natl Acad Sci U S A 2005;102:1481314818. [PubMed: 16192356]

32. Kalra N, Roy P, Prasad S, Shukla Y. Resveratrol induces apoptosis involving mitochondrial pathways in mouse skin tumorigenesis. Life Sci 2008;82:348-358. [PubMed: 18201729]

33. Mori A, Lehmann S, O'Kelly J, Kumagai T, Desmond JC, Pervan M, et al. Capsaicin, a component of red peppers, inhibits the growth of androgen-independent, p53 mutant prostate cancer cells. Cancer Res 2006;66:3222-3229. [PubMed: 16540674]

34. Qanungo S, Das M, Haldar S, Basu A. Epigallocatechin-3-gallate induces mitochondrial membrane depolarization and caspase-dependent apoptosis in pancreatic cancer cells. Carcinogenesis 2005;26:958-967. [PubMed: 15705601] 
35. Mohan KV, Gunasekaran P, Varalakshmi E, Hara Y, Nagini S. In vitro evaluation of the anticancer effect of lactoferrin and tea polyphenol combination on oral carcinoma cells. Cell Biol Int 2007;31:599-608. [PubMed: 17258915]

36. Cao J, Liu Y, Jia L, Zhou HM, Kong Y, Yang G, et al. Curcumin induces apoptosis through mitochondrial hyperpolarization and mtDNA damage in human hepatoma G2 cells. Free Radic Biol Med 2007;43:968-975. [PubMed: 17697941]

37. Lazze MC, Savio M, Pizzala R, Cazzalini O, Perucca P, Scovassi AI, et al. Anthocyanins induce cell cycle perturbations and apoptosis in different human cell lines. Carcinogenesis 2004;25:1427-1433. [PubMed: 15016660]

38. Baxa DM, Luo X, Yoshimura FK. Genistein induces apoptosis in T lymphoma cells via mitochondrial damage. Nutr Cancer 2005;51:93-101. [PubMed: 15749635]

39. Sanchez AM, Sanchez MG, Malagarie-Cazenave S, Olea N, Diaz-Laviada I. Induction of apoptosis in prostate tumor PC-3 cells and inhibition of xenograft prostate tumor growth by the vanilloid capsaicin. Apoptosis 2006;11:89-99. [PubMed: 16374544]

40. Zhang Y, Tang L, Gonzalez V. Selected isothiocyanates rapidly induce growth inhibition of cancer cells. Mol Cancer Ther 2003;2:1045-1052. [PubMed: 14578469]

41. Sun W, Wang W, Kim J, Keng P, Yang S, Zhang H, et al. Anti-cancer effect of resveratrol is associated with induction of apoptosis via a mitochondrial pathway alignment. Adv Exp Med Biol 2008;614:179-186. [PubMed: 18290328]

42. Kroemer G, Galluzzi L, Brenner C. Mitochondrial membrane permeabilization in cell death. Physiol Rev 2007;87:99-163. [PubMed: 17237344]

43. Hantz HL, Young LF, Martin KR. Physiologically attainable concentrations of lycopene induce mitochondrial apoptosis in LNCaP human prostate cancer cells. Exp Biol Med (Maywood) 2005;230:171-179. [PubMed: 15734720]

44. Larrosa M, Tomas-Barberan FA, Espin JC. The dietary hydrolysable tannin punicalagin releases ellagic acid that induces apoptosis in human colon adenocarcinoma Caco- 2 cells by using the mitochondrial pathway. J Nutr Biochem 2006;17:611-625. [PubMed: 16426830]

45. Meulmeester E, Jochemsen AG. p53: a guide to apoptosis. Curr Cancer Drug Targets 2008;8:87-97. [PubMed: 18336191]

46. Alkhalaf M. Resveratrol-induced apoptosis is associated with activation of p53 and inhibition of protein translation in T47D human breast cancer cells. Pharmacology 2007;80:134-143. [PubMed: 17534123]

47. Hastak K, Agarwal MK, Mukhtar H, Agarwal ML. Ablation of either p21 or Bax prevents p53dependent apoptosis induced by green tea polyphenol epigallocatechin-3-gallate. FASEB J 2005;19:789-791. [PubMed: 15764647]

48. Singh RP, Tyagi A, Sharma G, Mohan S, Agarwal R. Oral silibinin inhibits in vivo human bladder tumor xenograft growth involving down-regulation of survivin. Clin Cancer Res 2008;14:300-308. [PubMed: 18172282]

49. Schmidt F, Knobbe CB, Frank B, Wolburg H, Weller M. The topoisomerase II inhibitor, genistein, induces G2/M arrest and apoptosis in human malignant glioma cell lines. Oncol Rep 2008;19:10611066. [PubMed: 18357397]

50. Johnson ME, Howerth EW. Survivin: a bifunctional inhibitor of apoptosis protein. Vet Pathol 2004;41:599-607. [PubMed: 15557069]

51. Mai Z, Blackburn GL, Zhou JR. Genistein sensitizes inhibitory effect of tamoxifen on the growth of estrogen receptor-positive and HER2-overexpressing human breast cancer cells. Mol Carcinog 2007;46:534-542. [PubMed: 17295235]

52. Tian B, Wang Z, Zhao Y, Wang D, Li Y, Ma L, et al. Effects of curcumin on bladder cancer cells and development of urothelial tumors in a rat bladder carcinogenesis model. Cancer Lett 2008;264:299-308. [PubMed: 18342436]

53. Rahman KW, Li Y, Wang Z, Sarkar SH, Sarkar FH. Gene expression profiling revealed survivin as a target of 3,3'-diindolylmethane-induced cell growth inhibition and apoptosis in breast cancer cells. Cancer Res 2006;66:4952-4960. [PubMed: 16651453] 
54. Tang Y, Zhao DY, Elliott S, Zhao W, Curiel TJ, Beckman BS, et al. Epigallocatechin-3 gallate induces growth inhibition and apoptosis in human breast cancer cells through survivin suppression. Int $\mathbf{J}$ Oncol 2007;31:705-711. [PubMed: 17786300] 


\section{Extrinsic-Pathway}

(Receptor-Mediated)

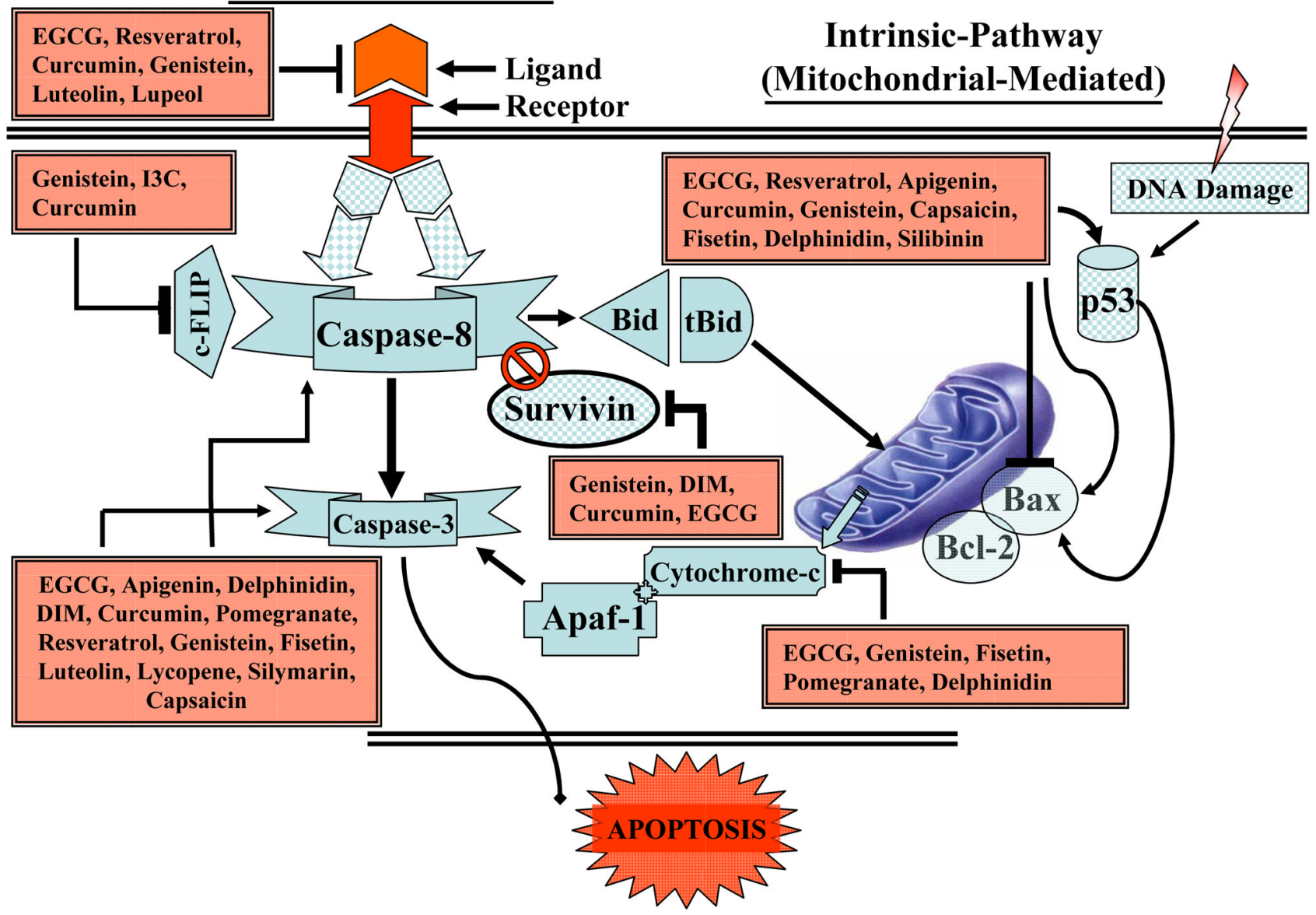

FIG. 1.

Dietary agents known to induce apoptosis by interfering with the extrinsic and the intrinsic apoptotic pathways. In the extrinsic pathway, a specific ligand binds to its corresponding cell surface death receptor and promote the recruitment of adapter molecule FADD to activate caspase- 8 which trigger the activation of downstream effector caspases such as caspase-3, thereby propagating apoptosis. The intrinsic pathway of apoptosis relies on the permeabilization of mitochondrial membrane to release the apoptogenic mitochondrial proteins which translocate to mitochondria where they induce the release of cytochrome $c$ either directly or through complexes with membrane proteins. Cytochrome $c$ together with Apaf-1 and procaspase- 9 forms apoptosome where activation of caspase- 9 occurs. The two pathways of apoptosis merge as caspase- 9 is capable of either directly or indirectly activating caspase- 8 which mediates the proteolytic activation of BID. EGCG, resveratrol, curcumin, genistein, luteolin, lupeol, and indole-3-carbinol target the death receptor pathway whereas EGCG, resveratrol, apigenin, fisetin, pomegranate, delphinidin, lupeol, curcumin, genistein, luteolin, indole-3-carbinol, capsaicin and silibinin target the mitochondrial pathway of apoptosis. 